\title{
Tree Structured Multi-Level Control System Design Based on MPC-EKF for Power Quality Enhancement with Selective Harmonic Elimination
}

\author{
N Narender Reddy, Jarupula Somla, A Srujana
}

\begin{abstract}
In this paper we propose to design a Tree Structured Multi Level Control System based on Model Predictive Control Algorithm with Extended Kalman Filter (MPC-EKF) to enhance the quality of power. The proposed MPC-EKF predicts the non-linear/unbalanced loads by the use of MPC and along with the prediction there is the need to detect the mode of the grid either grid connected or islanding mode which can be done with the help of EKF and further Improved Particle Swarm Optimized Selective harmonic Elimination (IPSO-SHE) is used to minimise the harmonics. Our proposed TSML control system has been developed in the MATLAB and tested with different load conditions. The simulation results of the proposed TSMLC system when compared with the existing control systems shows the impact of the proposed work.
\end{abstract}

Keywords: Distribution Grids, Tree structure Multilevel(TSML) Control system, , Islanding Model Predictive Controller,Extended Kalman Filter (EKF), Particle swarm Optimization (PSO), Selective Harmonic Elimination (SHE).

\section{INTRODUCTION}

DG units have desirable features such as environment support, energy expansion, lower infrastructure cost and deregulation of energy market. The DG units exist in the micro grid those are connected at Point of Common Coupling (PCC) is responsible for the delivering of power and those has to be in a position to exchange power between grid and loads [1][2]. The micro grid can operates in 2 modes, one mode is grid connecting mode and another mode is islanding mode. [3][4]. In grid-connecting mode, the object of the micro grid is to compensate both the active power and reactive power generated by the DG units and to meet the required local load demands [5]. When operating in Islanding mode the rest of the system is disconnected and operate independently[6].

The major issues that affects the quality of power in micro grids are problems related to Total Harmonic Distortion (THD) at the inverter side load voltage [7].While surveying the problems arises against power quality, the major problems are due to the improper design of controller, grid

connection, mode detection, harmonics etc. There were many

Revised Version Manuscript Received on August 19, 2019

N Narender Reddy, Research scholar KoneruLakshmaiah Education Foundation, Vaddeswaram, Guntur, A.P, India(email: nnr_rin@yahoo.co.in)

Jarupula Somla, Professor in EEE Dept, KoneruLakshmaiah Education Foundation, Vaddeswaram, Guntur, A.P, India

A Srujana, Professor in EEE Dept, Sri Venkateswara Engineering College, Suryapet, Telangana State, India papers [8-14] to solve these problems separately but none paper will solve all those problems together because of its cost. So there is a need to design a control system with suited controller which eliminates all the problems of mode detection and harmonic elimination in a optimized manner. Hence this paper designs a TSML controller which predicts the non linear /unbalanced loads with the help of proposed of Model Predictive Control (MPC) methodology. Along with the prediction, there is the need to detect the islanding mode of the controller, so the Extended Kalman filter is used. After that, to eliminate the overall harmonic distortion problems, the IPSO-SHE is proposed by adapting the inertia weight.

\section{SYSTEM DESCRIPTION}

The proposed system consist of various DG units like solar and wind energy sources with battery storage, utility grids and various load and TSMLC connected at PCC as shown in fig.1.the TSMLC consist of various controllers like A Control system based on MPC with EKF, A Bottom-up controller and A Top-down controller .

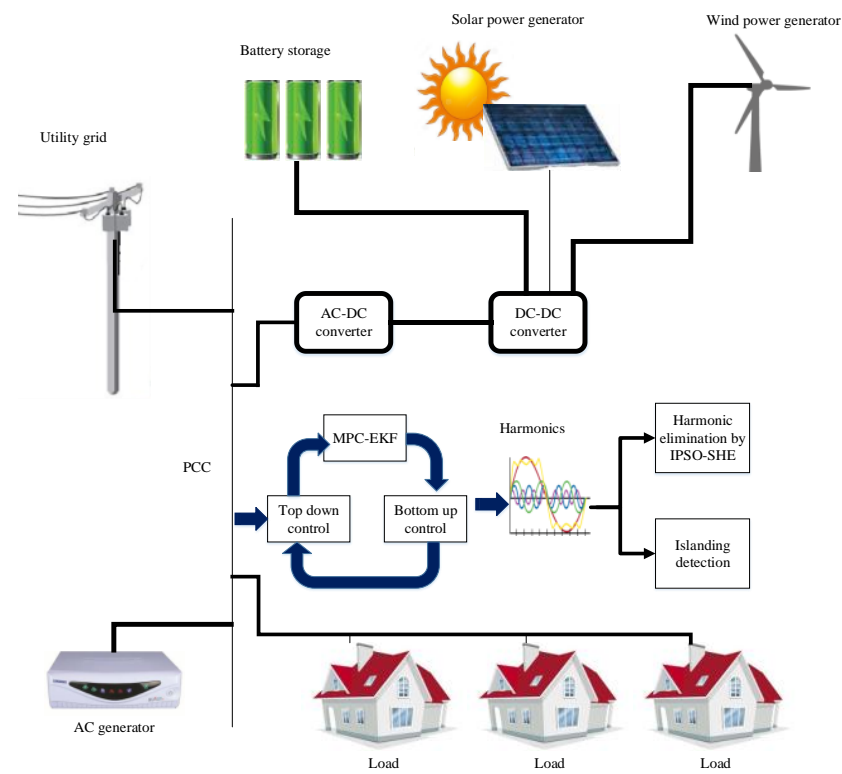

Figure 1: Block diagram of the proposed system with TSMLC 


\section{PROPOSED SYSTEM MODEL}

The proposed TSMLC we are considering in the micro grid is connected to the main grid with various loads.

\subsection{Load Model}

Here we consider a continuous-valued variable, $0 \leq \omega_{c}(k)$ $\leq 1$, associated to each controllable load and with sampling time k. This variable represents the percentage of required power level to be curtailed at time $\mathrm{k}$ in order to keep the microgrid operations viable. If limitations are absent at a certain time $\mathrm{k}^{\hat{}}$, an equality constraint can be set, $\omega_{c}\left(k^{\wedge}\right)=0$.

\subsection{Storage System model}

The storage unit in discrete time can write as:

$$
s^{a}(k+1)=s^{a}(k)+\left(\eta^{c}-1 / \eta^{d}\right) z^{b}(k)+1 / \eta^{d}\left[F^{\prime}(k) u(k)+f^{\prime} w(k)\right]-s^{a b}
$$

\subsection{Utility Grid interface model}

During grid connecting mode the micro grid is importing or exporting power from the utility grid in accordance with power demand. The grid interface can model by considering again a binary variable $\delta^{g}(k)$ and an auxiliary variable $E^{g}(k)$. Therefore the utility grid interface logical condition can be written as

$$
\begin{aligned}
& \text { And } \\
& P^{g}(n) \geq 0 \Leftrightarrow \delta^{g}(n)=1 \\
& E^{g}(n)=\left\{\begin{array}{ll}
e^{p}(n) P^{g}(n), & \text { if } \delta^{g}(n)=1 \\
e^{g}(n) P^{g}(n), & \text { otherwise }
\end{array}\right\} \\
& \text { the performance of the microgrid can be written as: } \\
& C_{1}^{g} \delta^{g}(n)+C_{2}^{g} E^{g}(n) \leq C_{3}^{g}(n) P^{g}(n)+C_{4}^{g}
\end{aligned}
$$

\subsection{DG unit On/Off behaviour model}

The cost functions of DG unit can narrate by considering two auxiliary variables such as $\mathrm{SUi}(\mathrm{k})$ and $\mathrm{SDi}(\mathrm{k})$ for the ith DG generation unit, at time $\mathrm{k}$. The combined constraints of these variables are expressed as:

$$
\begin{aligned}
& S U_{i}(k) \geq c_{i}^{S U}(k)\left[\delta_{i}(k)-\delta_{i}(k-1)\right] \\
& S D_{i}(k) \geq c_{i}^{S D}(k)\left[\delta_{i}(k-1)-\delta_{i}(k)\right] \text { with } i=1,2 . N_{g},(5) \\
& S U_{i}(k) \geq 0 \\
& S D_{i}(k) \geq 0
\end{aligned}
$$

\subsection{Operating Conditions of DG}

The DG operating condition with combined inequalities at each sampling time $\mathrm{k}$, is written as:

$$
\begin{array}{ll}
\delta_{i}(k)-\delta_{i}(k-1) \leq \delta_{i}(\tau), & \text { for Off / On switch } \\
\delta_{i}(k-1)-\delta_{i}(k) \leq 1-\delta_{i}(\tau), & \text { for On } / \text { Off switch }
\end{array}
$$

\subsection{Problem formulation}

The behaviour of the MPC for each sampling time k can be expressed by considering an auxiliary variable $\sigma_{i}(k)$ which narrate for the ith DG unit generation costs and the vector $\mathrm{z}(\mathrm{k})$, which collects all the auxiliary variables as follows:

$$
\begin{gathered}
\qquad z(k)=\left[\sigma^{\prime}(k) C^{g}(k) S U^{\prime}(k) S D^{\prime}(k) z^{a}(k)\right] \in R^{3 N_{g}+2} \\
\text { Where } u_{k}^{T-1} \text { denotes the input sequence at time } k \text { is expressed as follows: } \\
\qquad u_{k}^{T-1}=[u(k), \ldots \ldots u(k+T-1)]
\end{gathered}
$$

\section{(7)}

With $u_{k}^{T-1}$ given initial storage state and a final time $\mathrm{T}$ at time step $\mathrm{k}$, the MPC algorithm calculate $u_{k}^{T-1}$ the by solving the following optimal control problem expressed by:

$$
J\left(s_{k}^{a}\right)=\min _{u_{k}^{T-1}} \sum_{j=0}^{T-1}\left[c_{u}(k+j)^{\prime}+c_{z}{ }^{\prime} z(k+j)\right]
$$

Subjected to utility grid interface and Storage mode.

With a new estimated state $s_{k+1 / k+1}^{a}=s_{k+1}^{a}$, the above optimization problem is repeated in order to design optimal feedback signal.

\subsection{Proposed TSML Controller design with EKF}

In this we propose to design a TSML Control system based on MPC with EKF to improve quality of power. The proposed TSMLC Is designed with number of controllers like A Control system based on MPC WITH EKF, A Bottom-up controller and A Top-down controller as shown in fig .2.

The proposed controller design forms a closed loop like a structure of tree and in the proposed design three different type of controller are utilized for the same objective such as to improve the power quality so called Tree structured multi-level Control system. The MPC control algorithm separates the control object into a steady-state sub problem and a transient sub problems. The bottom-up controller will take the responsibility for tracking the steady state error and the top-down controller take care about the improvement of transient responce. MPC also find out the existence of harmonics in the system by using EKF, which helps to identify either the grid is operating in grid connecting mode or in islanding mode. We can also reduce those harmonics affectively with the help of a novel Particle Swarm Optimization with Selective Harmonic Elimination (IPSO-SHE) method.

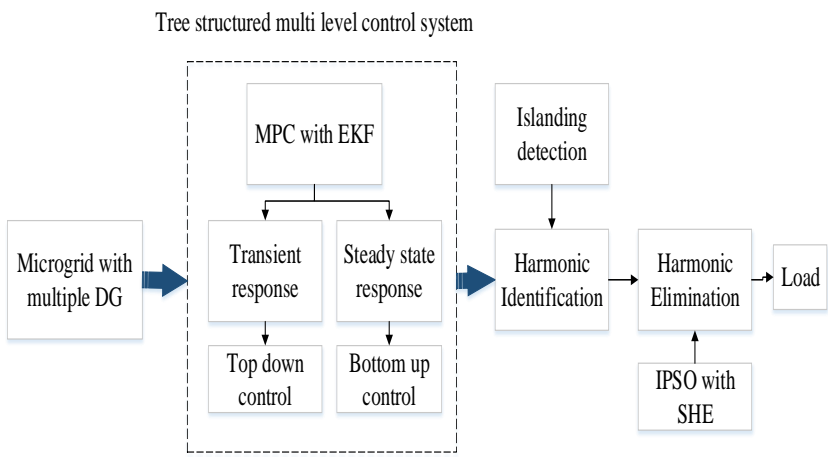

Figure 2: Process flow

The discrete time state space model of the micro grid can be expressed as:

$$
\begin{aligned}
& x^{\bullet}=A x+B_{1} w+B_{2} u \\
& y=C x+D_{1} w+D_{2} u
\end{aligned}
$$

Where is the periodic external disturbance which can be expressed as:

$$
\begin{aligned}
& w=C_{w} \xi \\
& \xi^{\bullet}=\overline{A_{\xi}}\left(f_{g}, f_{\mathrm{mg}}\right) \xi
\end{aligned}
$$

For a fundamental frequency $\mathrm{f}$ and consisting of only odd harmonics, then the state space model matrix $\mathrm{A}$ and $\mathrm{C}$ of a periodic signal can be represented as: 


$$
\begin{aligned}
& A=\left[\begin{array}{lr}
0 & h f \\
-h f & 0
\end{array}\right] \mathrm{h}=1,3,5,7 \ldots[\text { Odd harmonics }] \\
& C=\left[\begin{array}{lllllll}
1 & 0 & 1 & 0 & \ldots & \ldots & 1
\end{array}\right]
\end{aligned}
$$

The above model also calculates the phase angle and magnitude of that signal. The reference micro grid voltage and grid current can be tracked as:

$$
d=\left[\begin{array}{ll}
d v_{m g} & d i_{g}
\end{array}\right]^{T}=C_{d} \xi
$$

The state-space model represented above is known as the exogenous system. Based on this model an observer can be easily designed to produce from the measurement of and the reference $d$ being known.

The grid frequency fg may be subjected to minute but unknown fluctuations, which needs to be estimated from the measurement of grid voltage vg. In order to obtain this in discrete time an augmented model can be formed as:

$$
\begin{gathered}
\xi^{\bullet}=A_{\xi}\left(f_{g}, f_{m g}\right) \xi=\exp \left[\bar{A}_{\xi}\left(f_{g}, f_{m g}\right) T_{s}\right] \xi \\
\quad f_{g}^{+}=f_{g} \\
w=C_{w} \xi \\
d=C_{d} \xi
\end{gathered}
$$

Now, as the augmented model is nonlinear and hence an extended Kalman filter is required to estimate $\xi$ and observe fg at a time. The aim of the controller is to develop a control signal $\mathrm{u}$ such that the plant output y will track the known reference $d$. The control signal $u$ is separated in to

\begin{tabular}{|c|c|}
\hline & $\begin{array}{l}x_{s}^{*}=A x_{s}+B_{1} w+B_{2} u_{s} \\
y_{s}=C x_{s}+D_{1} w+D_{2} u_{s}\end{array}$ \\
\hline Subject to & $\left|u_{s}\right| \leq 1$ \\
\hline The dynam & as follows: \\
\hline & $\xi^{\bullet}=A_{\xi^{\wedge}}\left(f_{g}, f_{m g}\right) \xi^{\wedge}$ \\
\hline & $u_{s}=C_{\xi^{\wedge}}\left(f_{g}, f_{m g}\right) \xi^{\wedge}$ \\
\hline
\end{tabular}
steady state sub signal us and a transient sub signal ut as

$$
u=u_{s}+u_{t}
$$

Such that $u \rightarrow u_{s}$ and $u_{t} \rightarrow 0$ as $t \rightarrow \infty$.By letting $x \rightarrow x_{s}$ and $y \rightarrow y_{s}$ as $t \rightarrow \infty$ and during steady state operation, us, xs, ys can be written as:

Here the matrixes $C_{\xi^{\wedge}}$ and $A_{\xi^{\wedge}}$ are computed offline but the states will be optimized online to minimize the quadratic penalty on the steady state tracking error given by:

$$
\begin{aligned}
T E_{s} & =y_{s}-d \\
\text { The transient control signal defined as } u_{t} & =u-u_{s}, x_{t}=x-x_{s} \text { and } y_{t}=y-y_{s} \text { satisfy the } \\
x_{t}^{*} & =A x_{t}+B_{2} u_{t} \\
y_{t} & =C x_{t}+D_{2} u_{t}
\end{aligned}
$$

The aim of transient sub problem is to see that yt is equal to zero as quickly as possible, subjected to the constraint:

$$
\left|u_{s}+u_{t}\right| \leq 1
$$

Now it is required to see that the system is operating either in grid connecting mode or in islanding mode. This can be achieving with the help of harmonic signatures observed ny the EKF, and those harmonics can be eliminated with IPSO-SHE.

\subsection{Detection of Islanding and Elimination of Harmonic}

The two network configurations for islanding mode of operation and grid connecting mode of operation shows noticeable differences at PCC due to the presence of harmonic signatures and particularly 5 th harmonic content.
The harmonic voltage can be expressed as:

$$
V(t)=\sum_{n=1}^{5} a_{n} \sin n \alpha_{n}
$$

Here $\alpha_{n}$ represents the switching angles. The amplitude of the $n^{\text {th }}$ harmonic in terms of per unit can be expressed as:

$$
a_{n}=-\frac{4}{n \prod} \sum_{k=1}^{m}(-1)^{k} \cos n \alpha_{k}
$$

In this paper, the switching angles of the harmonic signatures are related to particles in the swarm. In order reduce the harmonics observed in the system, the fitness function can be expressed as:

Where

$$
F(x)=\min [T H D]
$$

$$
T H D=\left[\frac{1}{a_{1}^{2}} \sum_{n=5}^{\infty}\left(a_{n} / n\right)^{2}\right]^{1 / 2} \quad n=6 i \pm 1(i=1,2,3, \ldots) \text { (34) }
$$

Normally to eliminate the total harmonic distortion, the best switching angle of the controller should be calculated with the position of the angles and thereby it kept stable with the gbest and pbest position. In the PSO-SHE technique, to calculate the best switching angle is difficult because it changes the velocity of each angles toward its gbest and pbest positions at each time step. Hence by changing in velocity for each switching angles does not provide stability to the PSO. So IPSO-SHE is adopted by adding the adaptive inertia weight $\mathrm{w}$ along with the gbest and pbest values for each stream of execution. Due to weightage of the gbest and pbest, the angles doesn't change their position and the stability for PSO dynamically updated and balanced to provide the better exploration and exploitation. By this adaptive inertia weight for choosing the global and current best solution for the switching angle reduced harmonics and improves the power quality.

Table 1 shows the control parameters used in the proposed IPSO-SHE.

Table 1: IPSO-SHE Control parameters

\begin{tabular}{|c|c|}
\hline Control parameters & Value \\
\hline Population & 50 \\
\hline total iteration & 1000 \\
\hline $\mathrm{g}_{\max }$ & 0.9 \\
\hline $\mathrm{g}_{\min }$ & 0.4 \\
\hline $\mathrm{C}_{1}, \mathrm{C}_{2}$ & 2 \\
\hline
\end{tabular}

In every stream of execution, new search points are calculated from the present search points and the information regarding the gbest and pbest solutions is calculated by the following equation:

And

$$
v_{i}^{n+1}=g v_{i}^{n}+c_{1} r\left[\text { pbest } t_{i}^{n}-x_{i}^{n}\right]+c_{2} r\left[\text { gbest } t_{i}^{n}-x_{i}^{n}\right]
$$

$$
x_{i}^{n+1}=x_{i}^{n}+v_{i}^{n+1}
$$

Here $v$ is the particle velocity, $g$ is the inertia weight, $r$ represents a random number between 0 and $1, c_{1}$ and $c_{2}$ are the constriction factors, and $\mathrm{n}$ is the number of iterations. The inertia weight $g$ can be updated as:

$$
g=\frac{g_{\max }(m-n)+n g_{\min }}{m}
$$

Where $\mathrm{n}$ is the present number of execution and $\mathrm{m}$ is the total number of executions.

In every iteration, the proposed algorithm finds for best set of solutions and finally calculates the switching angles in order to generate the less THD. 
Tree Structured Multi-Level Control System Design Based on Mpc-Ekf for Power Quality Enhancement with Selective Harmonic Elimination

\section{SIMULATION RESULTS}

The test microgrid is connected at PCC through a three phase transformer where the main utility grid also connected. The proposed TSML controller connected between microgrid and utility grid in order to enhance power quality.

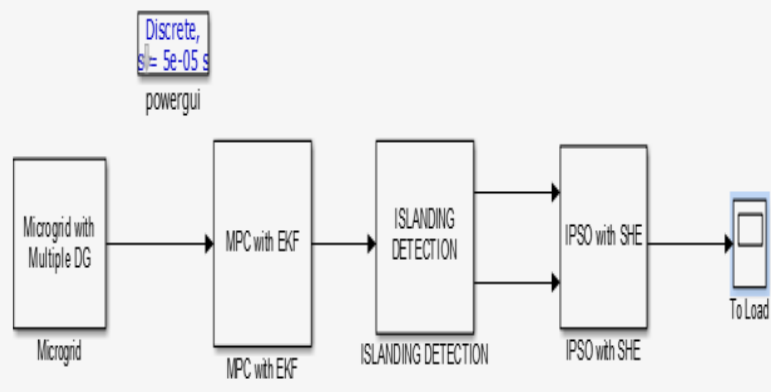

Figure 3: MATLAB circuit of the test microgrid system

Figure 3 shows the MATLAB circuit of the test micro grid.

Figure 4 shows the DC bus voltage and DC bus current variations at various time instants. The change in output shows the fluctuations in the power demand.

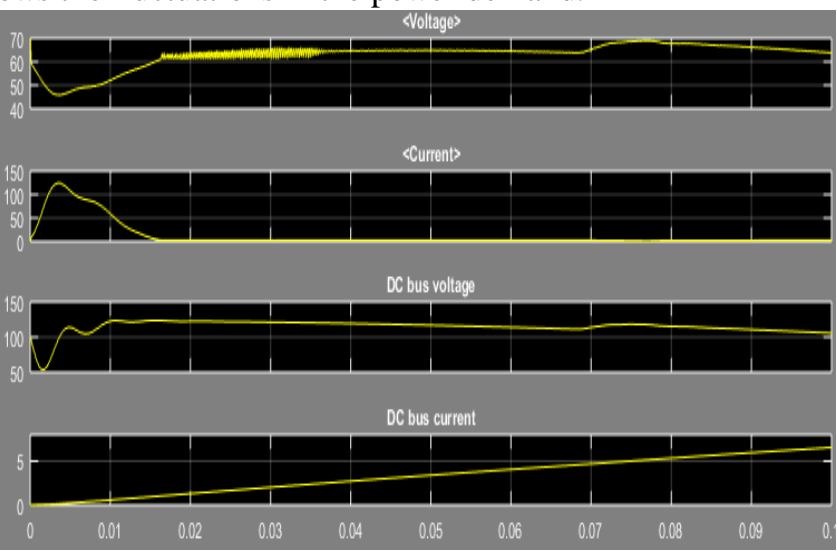

(a)

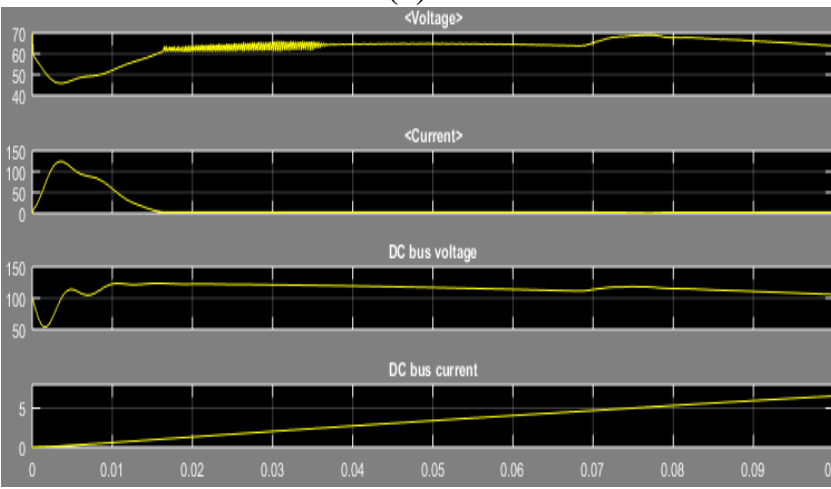

(b)

Figure 4: Output produced by (a) DG unit 1 (b) DG unit 2

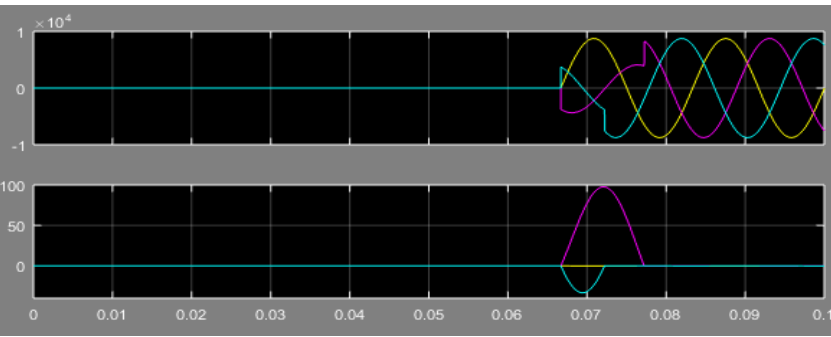

(a)

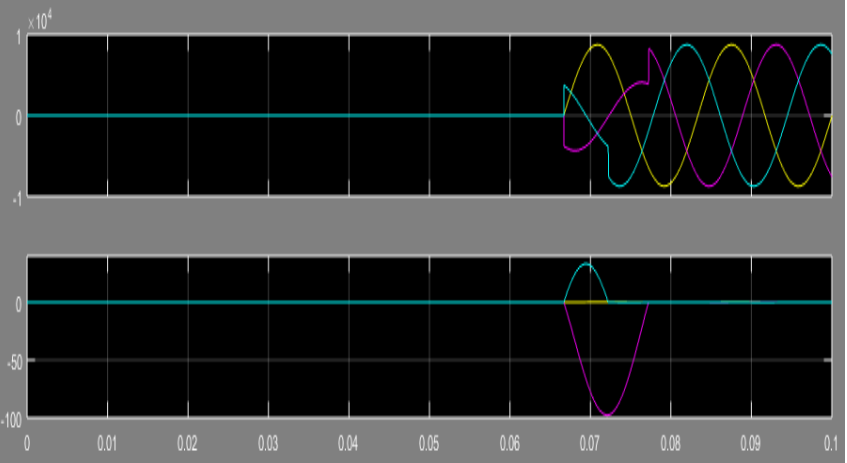

(b)

Figure 5: Three phase Microgrid output (a) voltage (b) current

Figure 5(a) and 5(b) shows the 3-ф output voltage and current of the microgrid supplied to the load with the help of PCC and utility grid. figure 6 show the output response of TSML controller in terms of voltage and current.

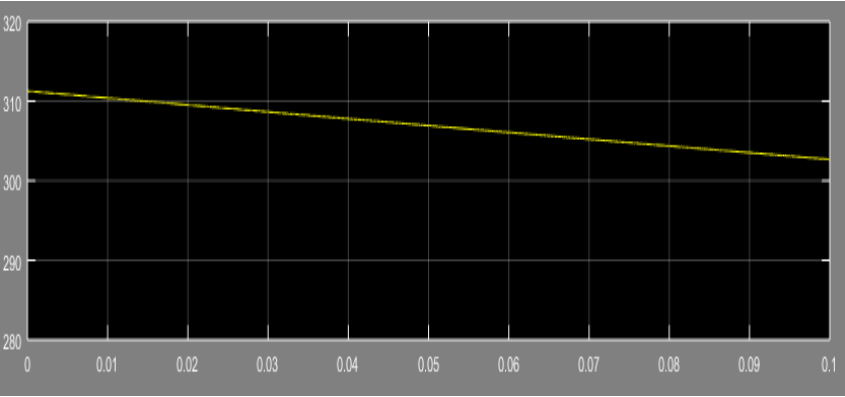

(a)

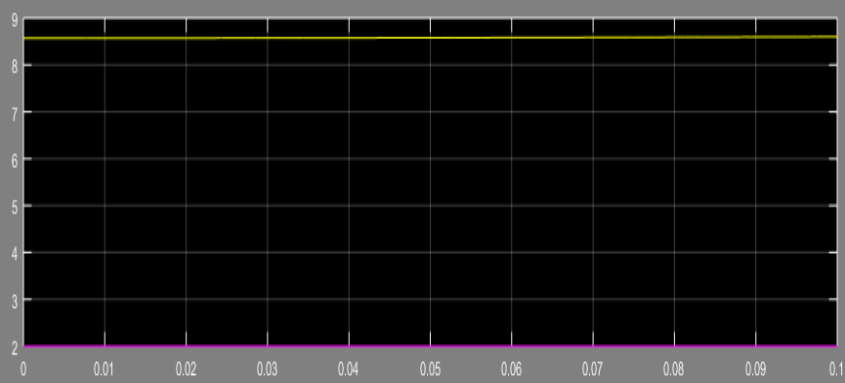

(b)

Figure 6: Response of proposed TSML controller (a) voltage (b) current

At each sampling time instant $\mathrm{k}$, MPC problem is solved by the proposed TSML controller. Table 2 reports the computation time required for TSML controller to solving the MPC problem as the prediction horizon increases.

Table 2: Computation time of TSML controller

\begin{tabular}{|c|c|c|c|c|}
\hline $\begin{array}{c}\text { No. of } \\
\text { horizon }\end{array}$ & $\begin{array}{c}\text { No. of } \\
\text { decision } \\
\text { variables }\end{array}$ & $\begin{array}{c}\text { No. of } \\
\text { constraints }\end{array}$ & $\begin{array}{c}\text { Average } \\
\text { time (s) }\end{array}$ & $\begin{array}{c}\text { Worst } \\
\text { case } \\
\text { time (s) }\end{array}$ \\
\hline 12 & 576 & 3561 & 3.1 & 5.7 \\
\hline 24 & 864 & 5397 & 4.5 & 6.9 \\
\hline 36 & 1152 & 7234 & 7.2 & 10.4 \\
\hline 48 & 1440 & 9070 & 9.8 & 16.2 \\
\hline 60 & 1728 & 10907 & 11.7 & 21.3 \\
\hline
\end{tabular}

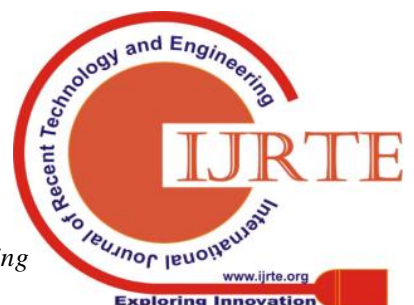




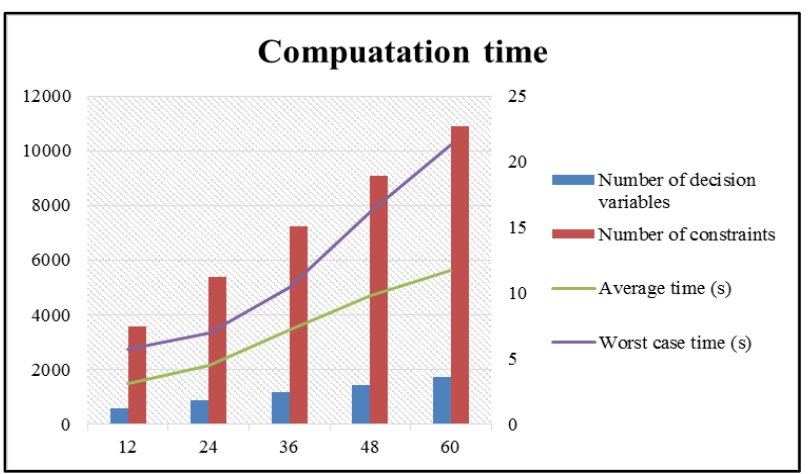

Figure 7: Computation time of TSML

Figure 7 shows the graphical representation of the computation time of our proposed TSML controller with respect to number of horizon, number of variables and number of constraints.

The EKF in the TSML control system observes the harmonic signatures produced by the output power delivered to the load. Figure. 8 shows the THD produced from proposed system.

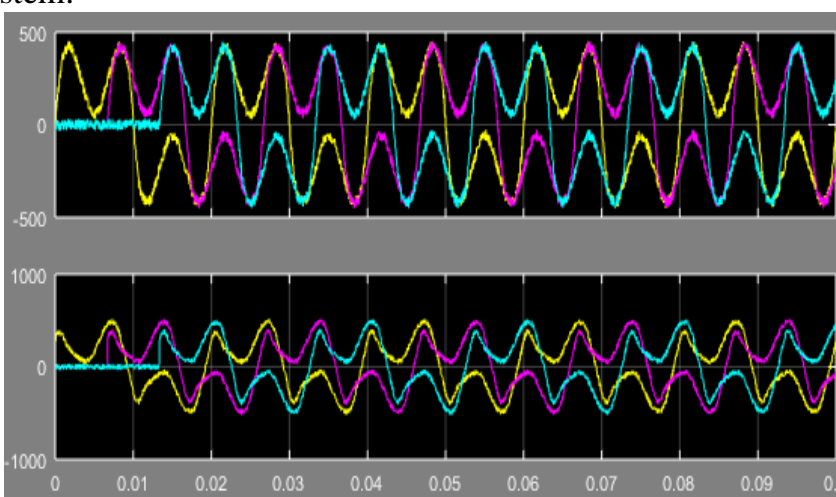

Figure 8: Total harmonic distortion resulted from the EKF

To keep the stability and to enhance the power quality now we introduced IPSO-SHE to minimises the harmonics detected by the EKF. Figure 9 shows the optimized output deliverd to load after elimination of harmonics.

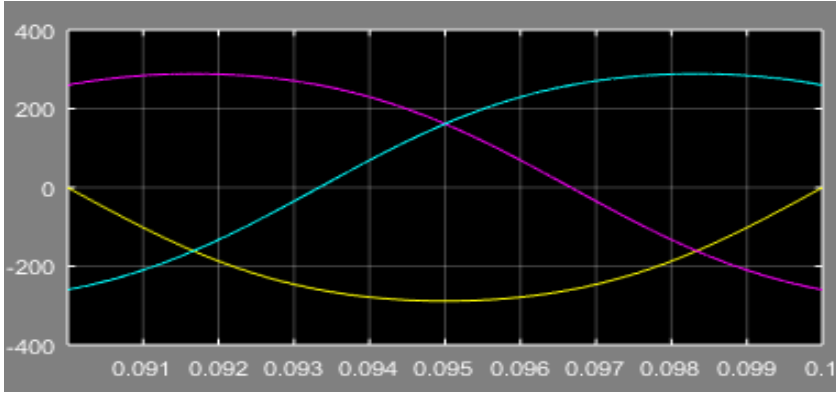

Figure 9: Optimized harmonic output with IPSO-SHE

Such an optimized output improves power quality of in micro grid. Table 3 shows the THD value in terms of micro grid voltage and grid current of the proposed IPSO-SHE when compared with traditional methods.

Table 3: THD value of IPSO-SHE in comparison with existing methods

\begin{tabular}{|l|c|c|c|}
\hline \multirow{2}{*}{ THD $(\%)$} & \multicolumn{2}{|c|}{ Existing methods } & \multirow{2}{*}{ IPSO-SHE } \\
\cline { 2 - 3 } & SHE & PSO-SHE & 3.206 \\
\hline $\begin{array}{l}\text { THD in terms of } \\
\text { voltage }\end{array}$ & 5.42 & 4.987 & 4.721 \\
\hline $\begin{array}{l}\text { THD in terms of } \\
\text { current }\end{array}$ & 6.31 & 5.99 & \\
\hline
\end{tabular}

Figure.10 shows the micro grid voltage and grid current THD values when compared with existing methods.

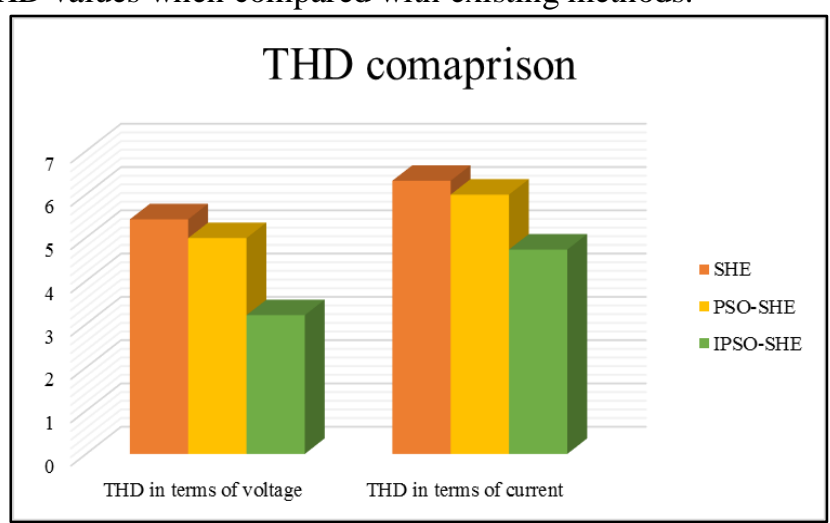

Figure 10: THD in terms of voltage and current comparison

From THD comparison we can observe this work minimise the THD values effectively when compared with existing methods.

The design of TSML controller is tested on the test microgrid system with storage. The operational cost required for the complete design of the proposed system when compared with some traditional methods are shownn table 4

Table 4: Comparison of Operation Cost of Microgrid with Storage

\begin{tabular}{|c|c|}
\hline Methods & Total $\operatorname{cost}(\mathbf{\$})$ \\
\hline MILP with storage & 858.10 \\
\hline MPC-MILP with storage & 440.3589 \\
\hline MPC-EKF with storage & 433.1523 \\
\hline
\end{tabular}

From table 4 we can observe that the proposed design greatly reduces the operational cost of the microgrid than the traditional methods which is represented by the comparison graph shown in figure 11.

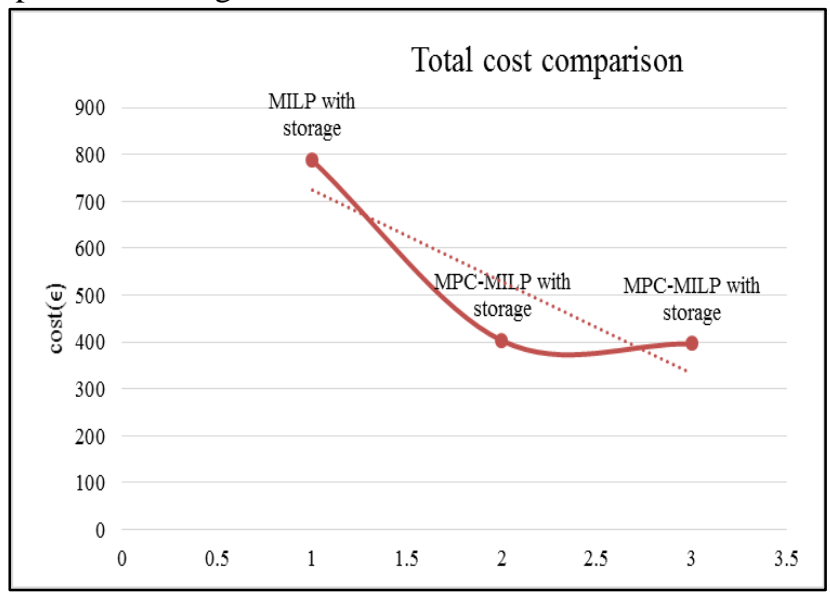

Figure 11: Total cost comparison

In figure 11 the grid line shows the reduction in operational cost of proposed system in comparison with the conventional designs. The dashed line shows the trend of operational cost reduction from the traditional methods. The operational cost of the proposed system is $433.1523 \$$ which is comparatively as lower than the traditional methods MILP (858.10 \$) and MPC- MILP (440.3589\$) with storage.

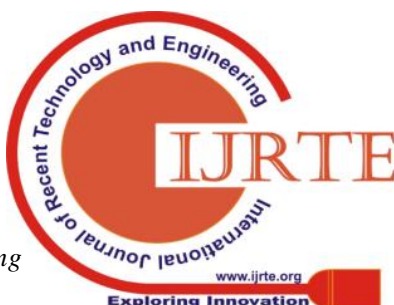




\section{CONCLUSION}

From the above results and comparison we conclude that our proposed methodology works more effectively when compared with the conventional methods in terms of computational time and operational cost. Also from the THD values in terms of voltage and current our proposed IPSO-SHE minimise harmonics produced at PCC effectively. Thus improve the quality of power and delivers stable power to the load continuously.

\section{REFERENCES}

1. Guerrero J M, Vasquez J C, Matas J, De Vicuña L G, and Castilla M, "Hierarchical control of droop-controlled AC and DC micro grids - A general approach toward standardization", IEEE Transactions on Industrial Electronics, Vol. 58, No. 1, pp. 158-172, 2011.

2. Bidram A, and Davoudi A, "Hierarchical structure of micro grids control system", IEEE Transactions on Smart Grid, Vol. 3, No. 4, pp. 1963-1976, 2012.

3. Balaguer I J, Lei Q, Yang S, Supatti U, and Peng F Z, "Control for grid-connected and intentional islanding operations of distributed power generation", IEEE Transactions on Industrial Electronics, Vol. 58, No. 1, pp. 147-157, 2011.

4. Yang, Nanfang, et al. "Compensation of droop control using common load condition in DC micro grids to improve voltage regulation and load sharing "International Journal of Electrical Power \& Energy Systems, Vol. 64, pp. 752-760, 2015.

5. Guerrero, Josep M., et al. "Advanced control architectures for intelligent micro grids, part I: decentralized and hierarchical control." IEEE Transactions on Industrial Electronics,Vol. 60,No. 4,pp.1254-1262, 2013.

6. Bouzid, Allal M., et al. "A survey on control of electric power distributed generation systems for microgrid applications " Renewable and Sustainable Energy Reviews, Vol. 44, pp. 751-766, 2015.

7. Hamzeh, Mohsen, HoushangKarimi, and HosseinMokhtari. "Harmonic and negative-sequence current control in an islanded multi-bus MV microgrid "IEEE Transactions on Smart Grid Vol. 5, No. 1 pp. 167-176,2014.

8. Tan, K.T., et al. 2013. A flexible AC distribution system device for a micro grid.IEEE Transactions on Energy Conversion28(3): 601-610.

9. Rao, L.N., 2016. A Flexible AC Distribution System for a Microgrid with a Photovoltaic System in Islanded Mode. International Journal for Modern Trends in Science and Technology, 2(5), pp.46-51.

10. Tan, K.T., et al. 2012. Centralized control for parallel operation of distributed generation inverters in micro grids. IEEE Transactions on Smart Grid3(4): 1977-1987.

11. Gundala Srinivasa Rao and Gattu Kesava Rao "An efficient islanding detection method in distributed generation using hybrid SVM-based decision tree" International Journal of Power Electronics 9(2): 1756-638X.

12. Yoshida, Hidehito, and Keiji Wada. 2015. Third-harmonic current suppression for power distribution systems under unbalanced installation of DG units.IEEE Transactions on Industrial Electronics62(9): 5578-5585.

13. Hamouda, N., Benalla, H., Hemsas, K., Babes, B., Petzoldt, J., Ellinger, T. and Hamouda, C., 2017. Type-2 Fuzzy Logic Predictive Control of a Grid Connected Wind Power Systems with Integrated Active Power Filter Capabilities. Journal of Power Electronics (JPE), 17(6), pp.1587-1599.

14. Kanieski, João Marcos, et al. 2013. Kalman filter-based control system for power quality conditioning devices.IEEE Transactions on Industrial Electronics60(11):5214-5227.

\section{AUTHORS PROFILE}

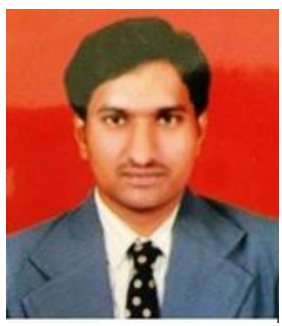

N Narender Reddy was born in 1984. He is currently pursuing Ph.D degree withdepartment of EEE, K L E F Deemed to be University, Guntur, Andhra Pradesh, India. He received B.Tech, degree in Electrical and Electronics Engineering from J.N.T.University, Hyderabad, A.P, India M.Tech., from J.N.T.University, Hyderabad, A.P, India. His current research interests include smart grids, renewable energy sources, and the application of AI techniques to power systems.

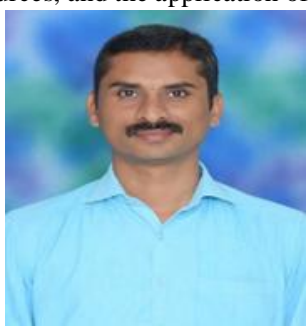

Dr.Jarupula Somlal was born in 1980 at present is working as Professor in the department of EEE, K L E F Deemed to be University, Guntur, Andhra Pradesh, India $\mathrm{He}$ received B.Tech, degree in Electrical and Electronics Engineering from J.N.T.University, Hyderabad, A.P, India M.Tech.,(Electrical Power Engineering) from J.N.T.University, Hyderabad, A.P India and Doctoral degree in Electrical \& Electronics Engineering at Acharya Nagarjuna University, Guntur, Andhra Pradesh, India. He received funding projects from Science and Engineering Research Board (SERB)-DST, India. He published 22 papers in International and National journals and presented various papers in national and International conferences. His current research interests include Hybrid Active Power filtering for power conditioning, Smart Grid, applications of intelligent techniques to power quality.

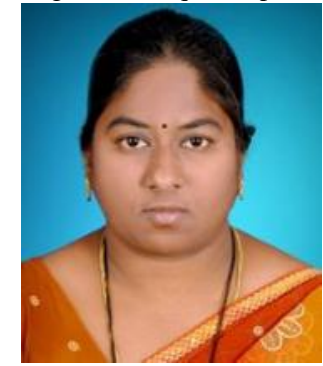

Dr. A Srujana was born in 1977 and a present is working as Professor in the department of EEE, Sri Venkateswara engineering college, Suryapet, Telangana state India. She received B.Tech, degree in Electrical and Electronics Engineering from KITS , Warangal, A.P, India, M.Tech and Doctoral degree in Electrical \& Electronics Engineering at J.N.T.University, Hyderabad, A.P, India Her current research interests include HVDC, FACTS controllers, microgrids, and Renewable energy sources. 